\title{
Poly (vinyl chloride) polyacrylonitrile composite membranes for the dehydration of acetic acid
}

\author{
G.H. Koops*, J.A.M. Nolten, M.H.V. Mulder** and C.A. Smolders \\ Department of Chemical Technology, University of Twente, P.O. Box 217, 7500 AE Enschede (The Netherlands)
}

(Received November 4, 1992; accepted December 23, 1992)

\begin{abstract}
Composite membranes have been prepared consisting of a poly (vinyl chloride) (PVC) top layer on either a dense polyacrylonitrile (PAN) layer (bi-layer membrane) or a porous PAN support layer (normal composite membrane) and studied with respect to the dehydration of acetic acid. Especially, the influence of the surface porosity of the porous support layer on the selectivity and flux was studied and it was shown that the lower the surface porosity the higher the selectivity of the composite membrane, especially at high acetic acid concentrations in the feed. From the results it can be concluded that the support material does contribute to the selectivity. Despite the low surface porosity relatively high fluxes could be obtained. Using a feed composition of $80 / 20 \mathrm{wt}$. $\%$ acetic acid/water at $80^{\circ} \mathrm{C}$ selectivities of $182-$ 274 and fluxes of $0.56-0.74 \mathrm{~kg} / \mathrm{m}^{2}-\mathrm{hr}$ were obtained, and with a feed composition of $98 / 2$ acetic acid/ water selectivities of $206-318$ and fluxes of $0.14-0.15 \mathrm{~kg} / \mathrm{m}^{2}-\mathrm{hr}$ were obtained.
\end{abstract}

Keywords: pervaporation; dehydration; acetic acid; composite membranes; poly(vinyl chloride); polyacrylonitrile

\section{Introduction}

Acetic acid/water mixtures are found in the chemical industry in the production of acetic acid, vinyl acetate, acetic anhydride, terephthalic acid, etc. For the separation of these mixtures normally techniques like fractionation distillation, azeotropic distillation and liquid-liquid extraction are used. These separation techniques consume considerable amounts of energy and therefore a demand for new and cheaper techniques is always welcome.

*Present address: National Institute of Materials and Chemical Research, 1-1 Higashi, Tsukuba, Ibaraki 305, Japan.

* To whom correspondence should be sent.
One of these cheaper alternatives might be pervaporation, a membrane separation process which is extremely suitable for the dehydration of organic solvents. The membranes used in pervaporation have to be sufficiently selective and permeable to be of economical interest. Applied to the dehydration of acetic acid at elevated temperatures the chemical and thermal resistance of the membrane material is also very important.

Poly (vinyl chloride) (PVC) appeared to be a suitable polymer to serve as a membrane material for the dehydration of acetic acid by pervaporation [1].

Once a satisfactorily selective polymer has been found a membrane has to be developed 
with a separating layer thin enough to obtain a maximum permeate flux. These required fluxes dictate a separating layer smaller than 1-2 $\mu \mathrm{m}$.

Homogeneous dense membranes of 1-2 $\mu \mathrm{m}$ thickness do not possess enough mechanical stability and need to be supported by a porous layer with a negligible contribution to the overall transport resistance, but with sufficient mechanical strength. Two of these types of membranes can be distinguished, viz. (i) integrally skinned membranes, where top layer and support layer originate from the same material, and (ii) composite membranes, where top layer and support layer consist of different materials.

Integrally skinned membranes can be obtained e.g. by casting a polymer solution followed by an evaporation step before the polymer solution is coagulated in a nonsolvent bath. Due to evaporation of the solvent the surface concentration becomes high enough resulting in a thin dense layer after phase inversion, while underneath the toplayer, where the polymer concentration is much lower, a porous layer will be formed. Techniques to obtain integrally skinned membranes have been developed by Pinnau and Koros (top layers of 300-1000 A) [2,3] and by Boom et al. [4] and Van't Hof et al. [5] (top layers of about $1 \mu \mathrm{m}$ ).

The first commercial pervaporation membrane is the composite membrane developed by GFT [6] for the dehydration of alcohols. This membrane consists of a crosslinked poly (vinyl alcohol) (PVA) top layer and a polyacrylonitrile (PAN) support layer. It combines high selectivity with a high flux.

In the development of a composite membrane the structure of the support layer is very important. To avoid capillary condensation inside the porous support the pores may not be too narrow. With the Kelvin relation (eqn. 1) it can be calculated at what pressures capillary condensation occurs as a function of the pore radius. $\ln \left(\frac{P}{P_{\mathrm{s}}}\right)=\left(\frac{-\gamma V_{\mathrm{m}}}{R T}\right) \cos \theta \frac{1}{r}$

On the other hand when the pore diameters are too large, problems might occur in achieving a thin defect-free coating layer (toplayer). A schematic representation of a composite membrane is given in Fig. 1.

Three different transport regions can be distinguished, each with a specific resistance, viz. the resistance belonging to region 1 which consists of a thin top layer and a thin layer of support material in series, the resistance belonging to region 2, which consists of a thin top layer and a thick layer of support material in series and the resistance belonging to region 3 , which only consists of a thin top layer. Because resistance (2) is much larger than the other two resistances (1) and (3) transport will not occur through region (2).

Ideal support layers for composite membranes must have a relatively high surface porosity and the separation properties of these composite membranes will be mainly determined by the top layer, unless the top layer material penetrates in the pores of the sub layer to a depth which results in a much higher resistance (3) compared to resistance (1).

A relatively low surface porosity results in a larger contribution of the support material to the separation properties of the composite membrane. This principle has been applied successfully by Henis and Tripodi [7] in the development of the Monsanto Prism ${ }^{\circledR}$ mem-

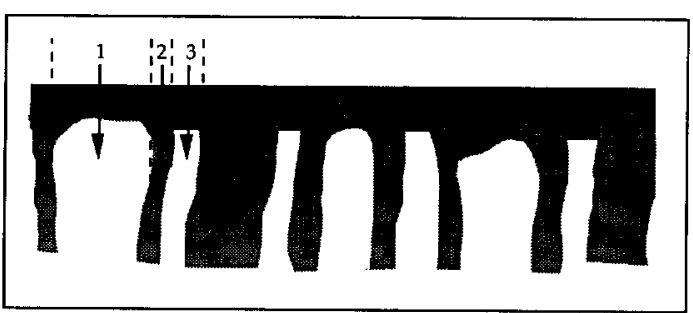

Fig. 1. Schematic representation of a composite membrane showing three different permeating regions. 
brane for hydrogen recovery; they plugged the pores of a polysulfone hollow fiber membrane (having a relatively low surface porosity) with silicon rubber resulting in a membrane with the intrinsic selectivity belonging to polysulfone.

To prepare a composite membrane with a defect-free top layer, e.g. by dip-coating or solution casting techniques, the coating solution has to show good wetting properties on the support material. Furthermore, the solvent for the top layer material may not attack the structure of the support layer.

In this paper the development of a composite membrane will be studied, using highly selective poly (vinyl chloride) (PVC) as top layer material and PAN as support material (which also by itself has a high selectivity).

\section{Experimental}

\section{Materials}

Polyacrylonitrile (PAN-7A) was obtained from Du Pont, Poly (vinyl chloride) (PVC, high $M W$ ) from Aldrich, polyester nonwoven (FO 2401) from Freudenberg, and PAN support layers from GFT.

Tetrahydrofuran (THF) was used as a solvent for $\mathrm{PVC}$ and $\mathrm{N}, \mathrm{N}$-dimethylformamide (DMF) was used as a solvent for PAN, both were of analytical grade and obtained from Merck.

\section{Membrane preparation}

PAN support layers were prepared by a phase inversion process. PAN (20 to 27.5 wt.\%) was dissolved in DMF and filtered over a $0.5 \mu \mathrm{m}$ metal filter. The filtered PAN solution was casted on a nonwoven support by a casting machine (Fig. 2) and coagulated in water at various temperatures. After rinsing with water for at least $24 \mathrm{hr}$ the casted PAN support layer was cut into pieces of $25 \times 20 \mathrm{~cm}$, immersed into an

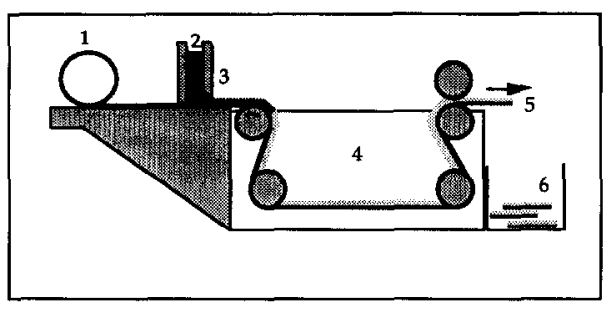

Fig. 2. Schematic representation of a membrane casting machine. (1) Non-woven, (2) polymer solution, (3) casting knife, (4) coagulation bath, (5) support layer, (6) rinsing bath.

ethanol bath for $4 \mathrm{hr}$ followed by immersion into a hexane bath for another $4 \mathrm{hr}$. Then the support layers were dried in air for at least two days before coating.

The PAN support layers (both prepared in our lab as well as obtained from GFT) were coated with a 3-10 wt.\% PVC solution in THF, either by dip-coating or by solution casting. Before dip-coating the $25 \times 20 \mathrm{~cm}$ PAN support layers were glued at the edges with the nonwoven side facing the glass plate, so that the PVC solution could not reach the back side of the support layer during immersion into the PVC solution. The PAN support layer glued on the glass plate was put into a glass box in a vertical position. The box was then filled with a PVC solution and emptied after waiting for 5$10 \mathrm{~min}$, by opening a small tap at the bottom of the box. The membrane was dried at room temperature for at least 1 day. In this way composite membranes with a dense PVC top layer on a porous PAN support layer were prepared. Dipcoating results in thinner toplayers than solution casting.

Also dense PVC/PAN bi-layers were prepared by first solution casting of a 15 wt.\% PAN solution on a glass plate followed by evaporation of the solvent in a nitrogen atmosphere. After the solvent had evaporated completely a 5-10 wt.\% PVC solution in THF was cast on top of the dense homogeneous PAN layer. Finally the solvent was allowed to evaporate in a 
nitrogen atmosphere and the bi-layer membranes were dried in a vacuum oven at $80^{\circ} \mathrm{C}$ for 1 week.

\section{Pervaporation}

Pervaporation experiments were carried out using a glassy set-up as described by Mulder et al. [8]. The permeate side was maintained at a pressure of $0.1-0.5 \mathrm{mmHg}$ by a Crompton Parkinson vacuum pump. The pressure was measured by an Edwards pirani meter. Permeate samples were taken every hour, during $8 \mathrm{hr}$. Steady-state was normally observed after $2-3$ hr. The permeate was analysed using a Varian 3700 gas chromatograph filled with a Poropack $Q$ column at a temperature of $190^{\circ} \mathrm{C}$.

\section{Support permeability}

The air permeability of all the support layers was measured with a Coulter Porometer II.

\section{Top layer thickness}

The top layer thickness of the composite membranes was determined from scanning electron microscopy (SEM) micrographs. Membrane samples were immersed in a 50/50 vol.\% water/ethanol mixture, frozen in liquid nitrogen followed by breaking. After drying, the samples were coated with a thin gold layer and studied by SEM. A SEM micrograph of a typical PVC/PAN composite membrane is given in Fig. 3. The PAN support layers contain large macrovoids starting from the nonwoven side and ending at a distance of about $3 \mu \mathrm{m}$ from the porous PAN top layer. A dense $0.3 \mu \mathrm{m}$ thin PVC top layer can be distinguished as the white line on top of the support layer.

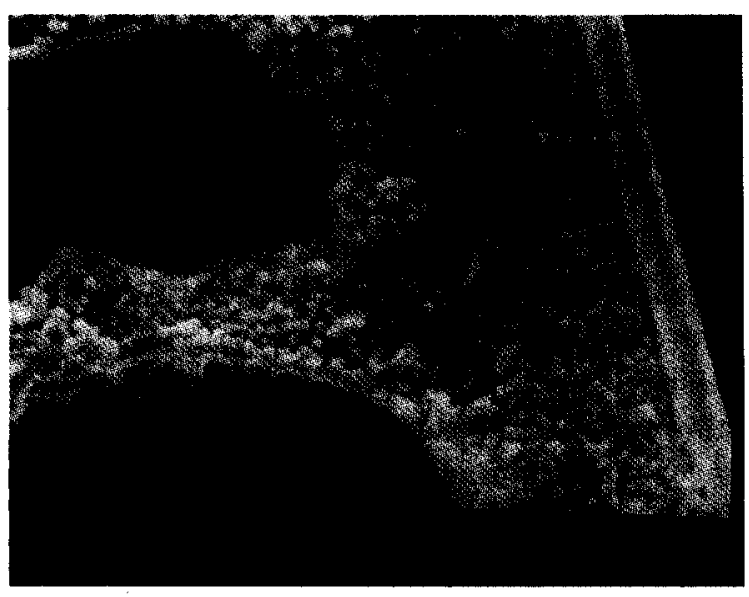

Fig. 3. Cross section of a PVC/PAN composite membrane; the thin white line is the PVC top layer $(0.3 \mu \mathrm{m})$ and the grey layer with the macrovoids is the porous PAN support layer.

\section{Results and discussion}

\section{Dense (bi-layer) membranes}

From a study on selectivity as a function of membrane thickness [9] it was found that the selectivity of PVC films drops dramatically when the membrane thickness is decreased below a certain value $(\sim 15 \mu \mathrm{m})$. Therefore, $\mathrm{a}$ relatively low selectivity can be expected for a composite membrane which consists of a highly porous PAN support layer covered by a thin PVC layer less than $1 \mu \mathrm{m}$ thick; in this case selectivity and flux will be mainly determined by the PVC layer. A possible contribution of the support material to the selectivity (through the effect of the transport pathway 1 in Fig. 1) can be altered by varying the porosity of the support layer.

To study the influence of the support material dense bi-layer membranes of PVC on PAN were prepared by solution casting of a PVC layer on top of a dense homogeneous PAN layer. Dense bi-layer membranes with different thicknesses were prepared and measured for the dehydration of acetic acid by pervaporation. 
The results of these measurements are presented in Table 1. From this table it can be concluded that these bi-layer membranes are extremely selective compared to dense PVC single-layers of comparable thickness, especially for the dehydration of $98 \mathrm{wt} . \%$ acetic acid.

In case of PVC/PAN bi-layers the selectivity seems to decrease with decreasing membrane thickness; this has also been observed for PVC, PAN and PSF single-layer membranes [9], but even a bi-layer membrane of $3 \mu \mathrm{m}$ total thickness shows a higher selectivity at $98 \mathrm{wt} . \%$ acetic acid than a $20 \mu \mathrm{m}$ PVC or PAN single-layer membrane (see Tables 3 and 4). Due to the presence of the PVC layer the degree of sorption in PAN at the PVC/PAN interface will be much lower compared to the equilibrium sorption value of the feed in PAN and this might therefore reduce craze formation in the PAN layer, resulting in a selectivity of bi-layer membranes being less dependent on the layer thickness compared to PVC and PAN as a singlelayer membrane.

The selectivity and flux of a dense PVC/PAN bi-layer membrane as a function of the feed composition is presented in Table 2.

The selectivity and flux values of a homogenous PVC single-layer and a homogeneous PAN single-layer membrane as a function of the feed composition are presented in Tables 3 and 4 , respectively.

Table 2 shows that the selectivity of the bilayer membrane increases with increasing concentration of acetic acid in the feed. This is due to the fact that acetic acid flux is almost independent of the feed composition up till $98 \mathrm{wt} . \%$ acetic acid. For separate PVC and PAN membranes the acetic acid flux and therefore the acetic acid content in the permeate increases rapidly going from $80 \mathrm{wt} . \%$ to $98 \mathrm{wt} . \%$ acetic acid in the feed, resulting in a decrease of selectivity.

The experimentally measured pervaporation selectivity and component fluxes through dense PVC and PAN single-layers and dense PVC/ PAN bi-layer membranes at different feed compositions and also the equilibrium sorption and sorption selectivity values for these membranes are shown in Table 5.

From Table 5 it can be concluded that the water flux of the bi-layer membrane is always in-between the water flux of the single-layer PVC and PAN membranes, while the acetic acid flux of the bi-layer is always lower than the lowest flux of the two single-layer membranes (in this case PAN).

The sorption selectivity of PVC and PAN is for both materials close to 1 (see Table 5).

\section{TABLE 1}

Selectivity and flux of dense PVC/PAN bi-layer membranes of variable total thickness for the dehydration of 80 wt.\% and $98 \mathrm{wt} . \%$ acetic acid at $80^{\circ} \mathrm{C}$

\begin{tabular}{llllrl}
\hline $\begin{array}{l}\text { PVC thickness } \\
(\mu \mathrm{m})\end{array}$ & $\begin{array}{l}\text { PAN thickness } \\
(\mu \mathrm{m})\end{array}$ & $\begin{array}{l}\text { Feed comp. } \\
\left(\mathrm{wt. \%} \mathrm{H}_{2} \mathrm{O}\right)\end{array}$ & $\begin{array}{l}\text { Permeate comp. } \\
\left(\text { wt.\% } \mathrm{H}_{2} \mathrm{O}\right)\end{array}$ & $\alpha$ & $\begin{array}{l}\text { Flux } \\
\left(\mathrm{kg} / \mathrm{m}^{2}-\mathrm{hr}\right)\end{array}$ \\
\hline 2 & 11 & 20.00 & 99.90 & 3996 & 0.023 \\
4.5 & 4.5 & 19.90 & 99.92 & 5027 & 0.035 \\
3 & 3 & 21.10 & 99.00 & 370 & 0.064 \\
1 & 2 & 21.20 & 98.90 & 334 & 0.099 \\
2 & & & & & \\
4.5 & 11 & 2.00 & 84.80 & 273 & 0.005 \\
3 & 4.5 & 2.10 & 99.30 & 6613 & 0.016 \\
1 & 3 & 1.90 & 90.20 & 475 & 0.026 \\
\hline
\end{tabular}


TABLE 2

Selectivity and flux of a $9 \mu \mathrm{m}$ dense PVC/PAN bi-layer membrane as a function of the feed composition for the dehydration of acetic acid by pervaporation at $80^{\circ} \mathrm{C}$

\begin{tabular}{llllll}
\hline $\begin{array}{l}\text { PVC thickness } \\
(\mu \mathrm{m})\end{array}$ & $\begin{array}{l}\text { PAN thickness } \\
(\mu \mathrm{m})\end{array}$ & $\begin{array}{l}\text { Feed comp. } \\
\left(\text { wt.\% } \mathrm{H}_{2} \mathrm{O}\right)\end{array}$ & $\begin{array}{l}\text { Permeate comp. } \\
\left(\text { wt.\% } \mathrm{H}_{2} \mathrm{O}\right)\end{array}$ & $\alpha$ & $\begin{array}{l}\text { Flux } \\
\left(\mathrm{kg} / \mathrm{m}^{2}-\mathrm{hr}\right)\end{array}$ \\
\hline 4.5 & 4.5 & 50.20 & 99.85 & 671 & 0.028 \\
4.5 & 4.5 & 40.20 & 99.80 & 742 & 0.029 \\
4.5 & 4.5 & 29.50 & 99.90 & 2387 & 0.030 \\
4.5 & 4.5 & 19.90 & 99.92 & 5027 & 0.035 \\
4.5 & 4.5 & 2.10 & 99.30 & 6613 & 0.016 \\
\hline
\end{tabular}

\section{TABLE 3}

Selectivity and flux of a $20 \mu \mathrm{m}$ dense PVC single-layer membrane as a function of the feed composition for the dehydration of acetic acid by pervaporation at $80^{\circ} \mathrm{C}$

\begin{tabular}{lllll}
\hline $\begin{array}{l}\text { PVC } \\
\text { thickness } \\
(\mu \mathrm{m})\end{array}$ & $\begin{array}{l}\text { Feed comp. } \\
\left(\text { wt.\% } \mathrm{H}_{2} \mathrm{O}\right)\end{array}$ & $\begin{array}{l}\text { Permeate } \\
\text { comp. } \\
\left.\text { (wt.\% } \mathrm{H}_{2} \mathrm{O}\right)\end{array}$ & $\alpha$ & $\begin{array}{l}\text { Flux } \\
\left(\mathrm{kg} / \mathrm{m}^{2} \text {-hr }\right)\end{array}$ \\
\hline 20 & 49.20 & 99.54 & 223 & 0.0174 \\
20 & 40.30 & 99.45 & 268 & 0.0168 \\
20 & 29.50 & 99.30 & 339 & 0.0174 \\
20 & 19.90 & 99.00 & 398 & 0.0192 \\
20 & 9.80 & 96.30 & 240 & 0.0192 \\
20 & 2.00 & 62.70 & 82 & 0.0232 \\
\hline
\end{tabular}

TABLE 4

Selectivity and flux of a $20 \mu \mathrm{m}$ dense PAN single-layer membrane as a function of the feed composition for the dehydration of acetic acid by pervaporation at $80^{\circ} \mathrm{C}$

\begin{tabular}{lllll}
\hline $\begin{array}{l}\text { PAN } \\
\text { thickness } \\
(\mu \mathrm{m})\end{array}$ & $\begin{array}{l}\text { Feed comp. } \\
\left(\text { wt.\% } \mathrm{H}_{2} \mathrm{O}\right)\end{array}$ & $\begin{array}{l}\text { Permeate } \\
\text { comp. } \\
\left(\text { wt.\% } \mathrm{H}_{2} \mathrm{O}\right)\end{array}$ & $\alpha$ & $\begin{array}{l}\text { Flux } \\
\left(\mathrm{kg} / \mathrm{m}^{2} \text {-hr }\right)\end{array}$ \\
\hline 20 & 49.70 & 99.92 & 1264 & 0.061 \\
20 & 40.00 & 99.92 & 1874 & 0.076 \\
20 & 29.70 & 99.91 & 2628 & 0.063 \\
20 & 21.80 & 99.84 & 2238 & 0.040 \\
20 & 10.90 & 99.60 & 2042 & 0.022 \\
20 & 1.80 & 83.70 & 280 & 0.006 \\
\hline
\end{tabular}

Therefore, the difference in driving force can be neglected in the case of equal feed compositions. The membrane with the highest degree of sorption should then have the highest flux, which is in agreement with the results shown in Table 5 .

Furthermore, a higher selectivity would be expected for the membrane with the lower degree of sorption. However, at a feed of $80 / 20$ wt.\% acetic acid/water the PAN membrane, showing a higher sorption value also exhibits a higher selectivity than PVC. In this case the PVC membrane did not show its intrinsic selectivity ( $\alpha=4750$; mean selectivity $\alpha= \pm 600$ ), which is, in accordance with the expectation, higher than the intrinsic selectivity of PAN $(\alpha=2240)$.

Due to the presence of the PVC layer the component concentration in PAN at the PVC/ PAN interface will always be lower than the concentration in PAN in case of equilibrium sorption and the component activities at the PVC/PAN interface are also lower than the activities at the feed side. Together with the experimentally obtained component fluxes concentration profiles in PVC, PAN and PVC/ PAN can be estimated. A schematic representation of possible concentration profiles of acetic acid and water at different feed compositions is given in Fig. 4 (dashed line represents the PVC/PAN interface).

In Figs. 4(a), 4(c) and 4(e) the average water concentration in the bi-layer membrane is inbetween the average water concentration of both single-layer membranes. The average acetic acid concentration is always lower than 
TABLE 5

Equilibrium sorption, sorption selectivity, acetic acid flux, water flux and pervaporation selectivity as a function of the feed composition for dense PVC and PAN single-layer membranes and dense PVC/PAN bi-layer membranes

\begin{tabular}{|c|c|c|c|c|c|c|}
\hline Membrane & $\begin{array}{l}\text { Feed } \\
\text { (acid/water) } \\
\text { (wt.\%) }\end{array}$ & $\begin{array}{l}\text { Sorption } \\
\text { (wt.\%) }\end{array}$ & $\begin{array}{l}\text { Sorption } \\
\text { selectivity } \\
{\left[\alpha_{\mathrm{w} / \mathbf{a}}^{\mathrm{s}}\right]}\end{array}$ & $\begin{array}{l}\text { Acetic acid } \\
\text { flux } \\
\left(\mathrm{g} / \mathrm{m}^{2}-\mathrm{hr}\right)\end{array}$ & $\begin{array}{l}\text { Water } \\
\text { flux }^{\mathrm{a}} \\
\left(\mathrm{g} / \mathrm{m}^{2}-\mathrm{hr}\right)\end{array}$ & $\begin{array}{l}\alpha \\
\text { perv }\end{array}$ \\
\hline PVC & $00 / 100$ & 0.8 & 1.0 & - & 4.4 & - \\
\hline PAB & $00 / 100$ & 12.4 & 1.0 & - & 101 & - \\
\hline $\mathrm{PVC} / \mathrm{PAN}^{\mathrm{b}}$ & $00 / 100$ & - & - & - & 53 & - \\
\hline PVC & $100 / 00$ & 10.6 & 0.1 & 49 & - & - \\
\hline PAN & $100 / 00$ & 6.9 & 1.0 & 10 & - & - \\
\hline PVC/PAN & $100 / 00$ & - & - & 2.4 & - & - \\
\hline PVC & $98 / 2$ & 9.6 & 1.52 & 19 & 32 & 82 \\
\hline PAN & $98 / 2$ & 5.9 & 3.69 & 2 & 11 & 280 \\
\hline PVC/PAN & $98 / 2$ & - & - & 0.1 & 16 & 6613 \\
\hline PVC & $80 / 20$ & 3.6 & 0.71 & 0.4 & 42 & 398 \\
\hline PAN & $80 / 20$ & 6.4 & 1.06 & 0.1 & 89 & 2238 \\
\hline PVC/PAN & $80 / 20$ & - & - & 0.003 & 35 & 5027 \\
\hline
\end{tabular}

aFluxes normalized to a membrane thickness of $9 \mu \mathrm{m}$.

${ }^{\mathrm{b}}$ Consists of $4.5 \mu \mathrm{m}$ PVC and $4.5 \mu \mathrm{m}$ PAN.

the average concentration in PAN, the less swollen of the two single-layers (Figs. $4 \mathrm{~b}, 4 \mathrm{~d}$ and 4f).

To verify this hypothesis the component concentrations have to be determined at the PVC/PAN interface and at a comparable distance in the PVC and PAN membranes. The "exponential 6-parameter model" of Brun et al. [10] was used to determine the activities at the PVC/PAN interface. This model expresses the component flux ratio as

$\frac{J_{i}}{J_{j}}=\frac{D_{i, 0} K_{j}}{D_{j, 0} K_{i}}\left[\frac{\exp \left(K_{i} S_{i} a_{i}^{\mathrm{p}}\right)-\exp \left(K_{i} S_{i} a_{i}^{f}\right)}{\exp \left(K_{j} S_{j} a_{j}^{\mathrm{p}}\right)-\exp \left(K_{j} S_{j} a_{j}^{f}\right)}\right]$

With the activities $a_{i}^{\mathrm{p}}$ and $a_{j}^{\mathrm{p}}$ at the permeate side equal to zero and a relation for the activity $a_{j}^{\mathrm{f}}$ as a function of the activity $a_{i}^{\mathrm{f}}$ at the feed side, values for $\left(D_{i, 0} K_{j}\right) /\left(D_{j, 0} K_{i}\right), K_{i} S_{i}$ and $K_{j} S_{j}$ can be determined by fitting relation (2) to the experimental values of $J_{i} / J_{j}$ as a function of $a_{i}^{\mathrm{f}}$. This has been done for homogeneous PAN and PVC membranes for the dehydration of acetic acid and has been worked out and described in the Appendix. One can see that the water flux/acetic acid flux ratio through homogeneous PAN and PVC membranes can be quite well described as a function of the water activity in the feed using this model.

Since, the flux ratio of a PVC/PAN bi-layer membrane is the same for the PVC layer as for the PAN layer the following relation can be derived

$$
\begin{aligned}
\frac{J_{i}}{J_{j}} & =\left(\frac{D_{i, 0} K_{j}}{D_{j, 0} K_{i}}\left[\frac{\exp \left(K_{i} S_{i} a_{i}^{\mathrm{p}}\right)-\exp \left(K_{i} S_{i} a_{i}^{\mathrm{f}}\right)}{\exp \left(K_{j} S_{j} a_{j}^{\mathrm{p}}\right)-\exp \left(K_{j} S_{j} a_{j}^{\mathrm{f}}\right)}\right]\right)_{\mathrm{PvC}} \\
& =\left(\frac{D_{i, 0} K_{j}}{D_{j, 0} K_{i}}\left[\frac{\exp \left(K_{i} S_{i} a_{i}^{\mathrm{p}}\right)-\exp \left(K_{i} S_{i} a_{i}^{\mathrm{f}}\right)}{\exp \left(K_{j} S_{j} a_{j}^{\mathrm{p}}\right)-\exp \left(K_{j} S S_{j} a_{j}^{\mathrm{f}}\right)}\right]\right)_{\mathrm{PAN}}
\end{aligned}
$$

The activities of the components $i$ and $j$ at the PVC/PAN interface in PVC and PAN, respectively are the same. Considering the activities in PAN at the PAN permeate interface equal to zero relation (3) can be rearranged to

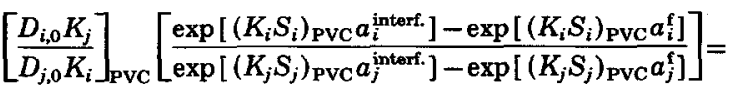

$$
\begin{aligned}
& {\left[\frac{D_{i, 0} K_{j}}{D_{j, 0} K_{i}}\right]_{\mathrm{PAN}}\left[\frac{1-\exp \left[\left(K_{i} S_{i}\right)_{\mathrm{PAN}} a_{i \text { intarf. }}\right]}{1-\exp \left[\left(K_{j} S_{j}\right)_{\mathrm{PAN}} a_{j}^{a_{\text {thorf }}}\right]}\right]}
\end{aligned}
$$




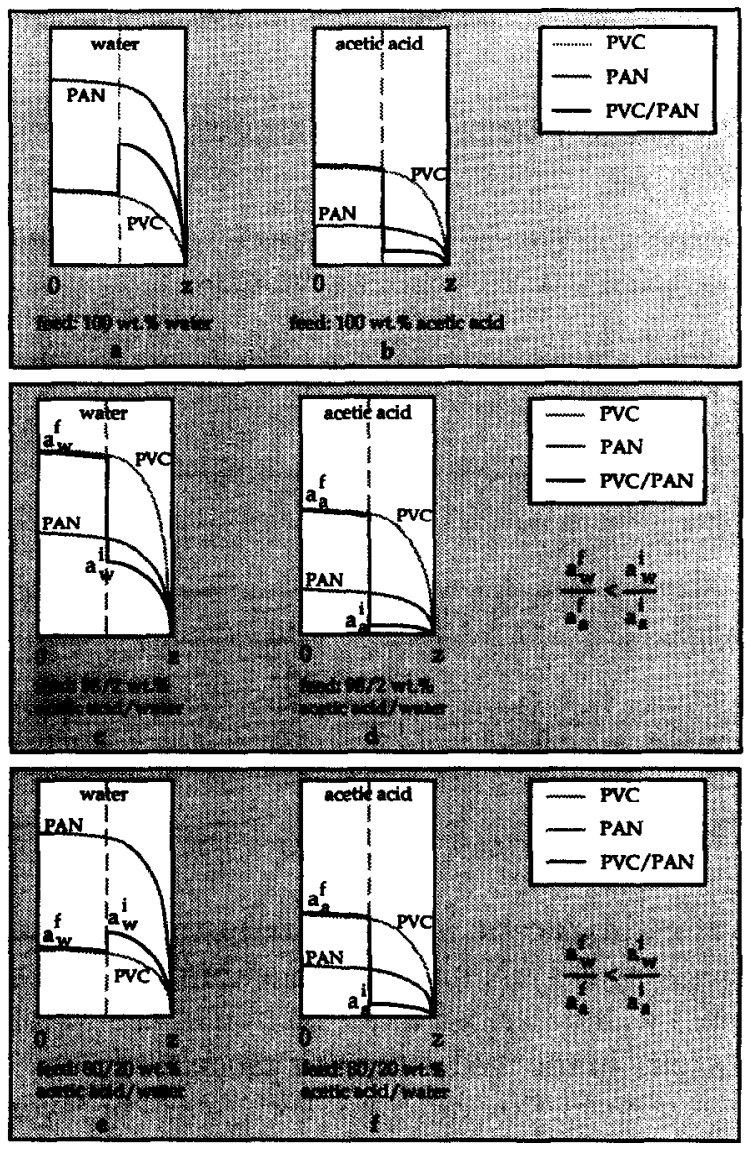

Fig. 4. Schematic representation of possible concentration profiles of water and acetic acid in dense PVC and PAN single-layer membranes and dense PVC/PAN bi-layer membranes during pervaporation using different feed compositions; (dashed line represents the PVC/PAN interface).

Using the values for $\left(D_{i, 0} K_{j}\right) /\left(D_{j, 0} K_{i}\right), K_{i} S_{i}$ and $K_{j} S_{j}$ determined for the single-layer membranes of PVC and PAN (see Appendix) the activities $a_{i}^{\text {interf. }}$ and $a_{j}^{\text {interf. }}$ at the PVC/PAN interface can be calculated.

Both calculated activities appeared to be higher than the activities at the feed side. This must be due to the fact that the constants $\left(D_{i, 0} K_{j}\right) /\left(D_{j, 0} K_{i}\right), K_{i} S_{i}$ and $K_{j} S_{j}$ of PAN in a bilayer membrane are different compared to the constants of PAN as a single-layer membrane.

In the case of a single-layer membrane the relation which describes the acetic acid activity as a function of the water activity in the membrane at the feed side is completely determined by free equilibrium sorption, while in the case of a bi-layer membrane this relation is dependent on the layer at the feed side of the PAN layer. A different relation for the acetic acid activity as a function of the water activity results in different values for the constants. Unfortunately, this relation cannot be determined.

\section{Composite membranes}

The influence of the PAN support layer was studied using GFT support layers as well as various support layers prepared by ourselves. These latter support layers are prepared by a phase inversion process using DMF as solvent and water as nonsolvent. In order to obtain different support layers mainly two parameters were varied, viz. the temperature of the coagulation bath and the polymer concentration of the casting dope. All the support layers were characterized by air permeability measurements and for some support layers the surface porosity and the average pore radius were determined. The results are presented in Table 6.

Changing the coagulation bath temperature from 7.5 to $17.5^{\circ} \mathrm{C}$ did not have much influence on the porosity as can be concluded from the air permeability data represented in Table 6. A large variety in surface porosity can be obtained by changing the polymer concentration in the casting dope; the porosity and the pore size decrease using higher polymer concentrations. Furthermore, it can be concluded that the pore diameter is smaller than $50 \mathrm{~nm}$ for all support layers. Therefore, no serious problems would be expected with respect to coating. Once the pore radius is known the relative pressure $P / P_{\mathrm{s}}$ inside these pores can be calculated using the Kelvin relation (eqn. 1 ). With $\theta=0$, which is generally accepted, it can be calculated that the relative pressure $P / P_{\mathrm{s}}=0.97$ for a pore ra- 
TABLE 6

Air permeability, average pore radius and surface porosity of differently prepared PAN support layers

\begin{tabular}{llllll}
\hline $\begin{array}{l}\text { Supp. } \\
\text { Nr. }\end{array}$ & $\begin{array}{l}\text { PAN } \\
(\text { wt.\%) }\end{array}$ & $\begin{array}{l}\text { Temp. } \\
\text { coag. bath } \\
\left({ }^{\circ} \mathrm{C}\right)\end{array}$ & $\begin{array}{l}\text { Air flow } \\
\left(1 / \mathrm{cm}^{2}-\mathrm{min}\right)^{\mathrm{b}}\end{array}$ & $\begin{array}{l}\text { Average }^{\mathrm{c}} \\
\text { pore radius } \\
(\mathrm{nm})\end{array}$ & $\begin{array}{l}\text { Surface }^{\mathrm{c}} \\
\text { porosity }^{2} \\
\left(\mathrm{~m}^{2} / \mathrm{m}^{2}\right)\end{array}$ \\
\hline 1 & GFT 89008 & & 0.394 & 5.1 & $1.22 \times 10^{-4}$ \\
2 & GFT 1411-B & & 1.026 & 9.2 & $4.34 \times 10^{-4}$ \\
3 & 20 & 7.5 & 0.412 & - & - \\
4 & 20 & 12.5 & 0.517 & - & - \\
5 & 20 & 15.5 & 0.520 & - & - \\
6 & 20 & 17.5 & 0.414 & 21.4 & $6.65 \times 10^{-4}$ \\
7 & 25 & 18.0 & 0.096 & 10.1 & $7.54 \times 10^{-5}$ \\
8 & 27.5 & 18.0 & 0.032 & 8.2 & \\
\hline
\end{tabular}

Represents PAN concentration in the casting solution.

${ }^{b}$ Feed pressure: 2 bar.

'Determined by Deutsche Carbone Geschäftseinheit GFT.

dius of $10 \mathrm{~nm}$ and $P / P_{\mathrm{s}}=0.98$ for a pore radius of $20 \mathrm{~nm}$. From these calculations it can be concluded that the occurrence of capillary condensation in these pores is very unlikely.

After coating with a 5 wt.\% PVC solution by solution casting or a dip-coating technique the performance of the composite membranes was measured for dehydration of $80 \mathrm{wt} . \%$ and 98 wt.\% acetic acid at $80^{\circ} \mathrm{C}$, respectively. The results of the coated GFT support layers are represented in Table 7.
Using the permeability of a homogeneous PVC membrane it can be estimated that for a $1.2 \mu \mathrm{m}$ thick PVC membrane (feed: $80 / 20 \mathrm{wt} . \%$ acetic acid/water) a flux of about $J=0.308 \mathrm{~kg}$ / $\mathrm{m}^{2}$-hr is obtained. Comparing this value with the flux obtained for a composite membrane with the same top layer thickness $(1.2 \mu \mathrm{m})$ and a surface porosity of only $0.0122 \%$ (see Table 6), giving a flux of $J=0.206 \mathrm{~kg} / \mathrm{m}^{2}$-hr using the same feed composition, it can be concluded that almost all the permeant has passed a PVC/PAN

\section{TABLE 7}

Selectivity and flux of PVC/PAN composite membranes for the dehydration of $80 \mathrm{wt} . \%$ and $98 \mathrm{wt} . \%$ acetic acid at $80^{\circ} \mathrm{C}$ using GFT supports

\begin{tabular}{|c|c|c|c|c|c|c|}
\hline $\begin{array}{l}\text { Supp. } \\
\text { Nr. }\end{array}$ & GFT & $\begin{array}{l}\text { Top layer } \\
\text { thickness } \\
(\mu \mathrm{m})\end{array}$ & $\begin{array}{l}\text { Feed comp. } \\
\text { (wt.\% } \mathrm{H}_{2} \mathrm{O} \text { ) }\end{array}$ & $\begin{array}{l}\text { Permeate } \\
\text { comp. } \\
\left(\text { wt. } \% \mathrm{H}_{2} \mathrm{O} \text { ) }\right.\end{array}$ & $\alpha$ & $\begin{array}{l}\text { Flux } \\
\left(\mathrm{kg} / \mathrm{m}^{2}-\mathrm{hr}\right)\end{array}$ \\
\hline $1^{\bullet}$ & 89008 & 1.2 & 19.70 & 96.80 & 123 & 0.206 \\
\hline $2^{a}$ & 1411-B & 1.5 & 20.20 & 96.70 & 116 & 0.178 \\
\hline $2^{b}$ & 1411-B & 0.5 & 20.10 & 95.00 & 76 & 0.581 \\
\hline $1^{*}$ & 89008 & 1.2 & 2.00 & 70.90 & 119 & 0.108 \\
\hline $2^{a}$ & 1411-B & 1.5 & 2.20 & 59.30 & 65 & 0.155 \\
\hline $2^{b}$ & 1411-B & 0.5 & 1.80 & 43.10 & 41 & 0.257 \\
\hline
\end{tabular}

alution casting.

bDip-coating. 
bi-layer (see pathway 1 in Fig. 1) with a relatively small resistance in the PAN layer. Therefore, this PAN layer has to be very thin.

In a former study [9] it was concluded that the selectivity of PVC decreases with decreasing membrane thickness. However, from experiments on dense PVC/PAN bi-layer membranes it can be concluded that these bi-layers, with a comparable thickness as a single PVC layer have a higher selectivity than a singlelayer PVC membrane. Therefore, a higher surface porosity of the PAN support results in a larger contribution of the thin PVC top layer to the overall membrane properties, which in that case should give lower selectivities due to surface and crazing effects [9]. This is especially the case at higher acid concentrations in the feed, because then the difference in selectivity of a PVC/PAN and a PVC membrane becomes even larger; this is supported by the data shown in Table 7, where support 1411-B has the larger surface porosity.

Changing the coagulation bath temperature and using a $20 \mathrm{wt}$.\% PAN solution similar surface porosities were obtained as for the GFT 89008 support; only the pore radius is 4 times larger (see Table 6). After dip-coating these supports with a $5 \mathrm{wt} . \%$ PVC solution the membranes were measured for pervaporation. The selectivity and flux for the dehydration of $\mathbf{8 0}$ wt.\% and 98 wt.\% acetic acid are represented in Table 8.

According to the air flow data presented in Table 6 the support layers show a small increase in porosity in the order $1<3<4<5$. This difference does not affect the separation properties for the dehydration of $80 \mathrm{wt} . \%$ acetic acid as can be concluded from Tables 7 and 8; the differences in porosity are too small.

However, using a feed of $98 / 2$ wt.\% acetic acid/water a significant increase of the water concentration in the permeate can be observed in the order $1>3>4>5$. At this feed concentration the selectivity of a thin PVC layer becomes so low that even small differences in the surface porosity of the support do have a significant influence on the selectivity of the composite membrane. The influence on flux is negligible.

Anyhow, it should be noted that the composite membranes with support layer numbers 3,4 and 5 are highly selective in the dehydration of $80 \mathrm{wt} . \%$ acetic acid and in addition have high fluxes as well. The selectivity at $98 \mathrm{wt} . \%$ acetic

\section{TABLE 8}

The influence of the coagulation bath temperature (support layer) on selectivity and flux of PVC/PAN composite membranes for the dehydration of $80 \mathrm{wt} . \%$ and $98 \mathrm{wt} . \%$ acetic acid at $80^{\circ} \mathrm{C}$

\begin{tabular}{|c|c|c|c|c|c|c|}
\hline $\begin{array}{l}\text { Supp. } \\
\text { Nr. }\end{array}$ & $\begin{array}{l}\text { Temp. } \\
\text { coag. bath } \\
\left({ }^{\circ} \mathrm{C}\right)\end{array}$ & $\begin{array}{l}\text { Top layer } \\
\text { thickness } \\
(\mu \mathrm{m})\end{array}$ & $\begin{array}{l}\text { Feed comp. } \\
\left(\text { wt. } \% \mathrm{H}_{2} \mathrm{O} \text { ) }\right.\end{array}$ & $\begin{array}{l}\text { Permeate } \\
\text { comp. } \\
\text { (wt.\% } \mathrm{H}_{2} \mathrm{O} \text { ) }\end{array}$ & $\alpha$ & $\begin{array}{l}\text { Flux } \\
\left(\mathrm{kg} / \mathrm{m}^{2}-\mathrm{hr}\right)\end{array}$ \\
\hline 3 & 7.5 & 0.5 & 19.90 & 97.70 & 171 & 0.624 \\
\hline 4 & 12.5 & 0.5 & 19.60 & 97.80 & 182 & 0.565 \\
\hline 5 & 15.5 & 0.5 & 19.70 & 97.70 & 173 & 0.581 \\
\hline 6 & 17.5 & 0.5 & 20.30 & 96.60 & 112 & 0.527 \\
\hline 3 & 7.5 & 0.5 & 1.90 & 66.90 & 104 & 0.252 \\
\hline 4 & 12.5 & 0.5 & 1.50 & 60.40 & 100 & 0.227 \\
\hline 5 & 15.5 & 0.5 & 1.40 & 47.40 & 63 & 0.270 \\
\hline 6 & 17.5 & 0.5 & 1.40 & 51.20 & 74 & 0.277 \\
\hline
\end{tabular}


TABLE 9

The influence of the PAN concentration in the casting solution on selectivity and flux of PVC/PAN composite membranes for the dehydration of $80 \mathrm{wt} . \%$ and $98 \mathrm{wt} . \%$ acetic acid at $80^{\circ} \mathrm{C}$

\begin{tabular}{lllllll}
\hline $\begin{array}{l}\text { Supp. } \\
\text { Nr. }\end{array}$ & $\begin{array}{l}\text { PAN } \\
(\text { wt.\%) }\end{array}$ & $\begin{array}{l}\text { Toplayer } \\
\text { thickness } \\
(\mu \mathrm{m})\end{array}$ & $\begin{array}{l}\text { Feed comp. } \\
\left(\text { wt.\% } \mathrm{H}_{2} \mathrm{O}\right)\end{array}$ & $\begin{array}{l}\text { Permeate } \\
\text { comp. } \\
\left(\mathrm{wt} \% \mathrm{H}_{2} \mathrm{O}\right)\end{array}$ & $\alpha$ & $\begin{array}{l}\text { Flux } \\
\left(\mathrm{kg} / \mathrm{m}^{2}-\mathrm{hr}\right)\end{array}$ \\
\hline 6 & 20 & 0.8 & 20.30 & 96.60 & 112 & 0.527 \\
7 & 25 & 1.0 & 20.60 & 97.90 & 180 & 0.364 \\
7 & 25 & 0.3 & 20.40 & 97.90 & 182 & 0.742 \\
8 & 27.5 & 1.0 & 20.75 & 97.30 & 138 & 0.392 \\
8 & 27.5 & 0.5 & 20.20 & 98.58 & 274 & 0.558 \\
& & & & & 74 & 0.277 \\
6 & 20 & 0.8 & 1.40 & 51.20 & 318 & 0.126 \\
7 & 25 & 1.0 & 1.50 & 82.90 & 206 & 0.153 \\
7 & 25 & 0.3 & 2.00 & 80.80 & 224 & 0.088 \\
8 & 27.5 & 1.0 & 1.65 & 79.00 & 261 & 0.140 \\
\hline
\end{tabular}

aRepresents PAN concentration in the casting solution.

acid is still too low, although the flux is sufficiently high. By decreasing the surface porosity of the support layer the selectivity may be improved.

A successful decrease of the surface porosity was achieved by increasing the polymer concentration of the casting solution (see Table 6). After dip-coating with a 3-5 wt.\% PVC solution these membranes gave the following selectivity and flux values for the dehydration of acetic acid (see Table 9 ).

From Table 9 it can be concluded that a further decrease of the porosity results in higher selectivities at relatively high concentrations of acetic acid in the feed. At a concentration of 98 wt.\% acetic acid in the feed the selectivity of the composite membrane increases spectacularly when the porosity of the support layer decreases. The fact that the selectivity increases using higher concentrations of acetic acid in the feed proves clearly that the support layer does contribute to the selectivity of the composite membrane (see Table 2). The fluxes of these membranes decrease with decreasing porosity, but are still acceptable.

\section{Conclusions}

Extremely high selectivities can be obtained for the dehydration of highly concentrated acetic acid mixtures using a bi-layer membrane consisting of a dense PVC layer on top of a dense PAN layer. However, the fluxes are low as expected.

For composite membranes with a porous support layer of PAN coated with a thin PVC layer two different regions can be distinguished where transport takes place, viz. a region which consists of a PVC/PAN bi-layer and a region which consists of a PVC single-layer. Each of these regions has a characteristic resistance. Due to the fact that the bi-layer shows higher selectivities than dense PVC single-layers of the same total thickness highly selective composite membranes can be developed by decreasing the surface porosity of the support.

\section{Acknowledgement}

The work described in this paper is part of the Brite-project RI1B-196. The European 
Community (BRITE), B.P. Chemicals Ltd and Deutsche Carbone GmbH Geschäftseinheit GFT are gratefully acknowledged for their financial support. The authors also wish to express their thanks for the porosity data and PAN support layers delivered by GFT.

\section{List of symbols}

\begin{tabular}{|c|c|}
\hline$a$ & activity (-) \\
\hline $\boldsymbol{A}$ & plasticizing constant $(-)$ \\
\hline$C$ & concentration $\left(\mathrm{mol} / \mathrm{m}^{3}\right)$ \\
\hline$D$ & $\begin{array}{l}\text { diffusion coefficient in membrane } \\
\left(\mathrm{m}^{2} / \mathrm{sec}\right)\end{array}$ \\
\hline$D_{0}$ & $\begin{array}{l}\text { diffusion coefficient at infinite dilu- } \\
\text { tion of the permeant in the mem- } \\
\text { brane }\left(\mathrm{m}^{2} / \mathrm{sec}\right)\end{array}$ \\
\hline$\gamma$ & interfacial tension $(\mathrm{N} / \mathrm{m})$ \\
\hline$J$ & flux $\left(\mathrm{kg} / \mathrm{m}^{2}-\mathrm{hr}\right)$ \\
\hline $\boldsymbol{K}$ & $\begin{array}{l}\text { intermediate constant of the model } \\
(-)\end{array}$ \\
\hline $\boldsymbol{P}$ & vapour pressure $\left(\mathrm{N} / \mathrm{m}^{2}\right)$ \\
\hline$P_{\mathrm{B}}$ & saturation pressure $\left(\mathrm{N} / \mathrm{m}^{2}\right)$ \\
\hline $\boldsymbol{r}$ & pore radius $(\mathrm{m})$ \\
\hline $\boldsymbol{R}$ & gas constant $(\mathrm{J} / \mathrm{mol}-\mathrm{K})$ \\
\hline$S$ & sorption coefficient $\left(\mathrm{mol} / \mathrm{m}^{3}\right)$ \\
\hline$T$ & temperature $(\mathrm{K})$ \\
\hline$\theta$ & contact angle $\left({ }^{\circ}\right)$ \\
\hline$V_{\mathbf{m}}$ & molar volume $\left(\mathrm{m}^{3} / \mathrm{mol}\right)$ \\
\hline$z$ & membrane thickness, distance (m) \\
\hline
\end{tabular}

\section{Subscripts}

$\begin{array}{ll}\text { a } & \text { acetic acid } \\ i & \text { component } i \\ j & \text { component } j\end{array}$

\section{Superscript}

interf. interface

i interface $\begin{array}{ll}\text { f } & \text { feed } \\ \text { p } & \text { permeate }\end{array}$

\section{References}

1 G.H. Koops, J.A.M. Nolten, M.H.V. Mulder and C.A. Smolders, Membrane development for the dehydration of acetic acid by pervaporation - PAN/PVC composite membrane and PSf integrally skinned membrane, Proc. 6th Int. Conf. on Pervaporation in the Chemical Industry, Ottawa, Canada, R. Bakish (Ed.), Bakish Materials Corporation, Englewood, NJ, in press.

2 I. Pinnau and W.J. Koros, Defect-free ultrahigh flux asymmetric membranes, U.S. Patent 4,902,422, 1990.

3 I. Pinnau and W.J. Koros, Structures and gas separation properties of asymmetric polysulfone membranes made by dry, wet, and dry/wet phase inversion, J. Appl. Polym. Sci., 43 (1991) 1491-1502.

4 R.M. Boom, J.A. van 't Hof, A.J. Reuvers, Th. van den Boomgaard and C.A. Smolders, Preparation of asymmetric gas separation membranes with a high selectivity by a dual bath wet spinning method, Proc. Int. Conf. on Chem. Eng., Chemcon '89, Trivandrum, India, 12-17 Dec. 1989.

5 J.A. van 't Hof, A.J. Reuvers, R.M. Boom, H.H.M. Rolevink and C.A. Smolders, Preparation of asymmetric gas separation membranes with high selectivity by a dual-bath coagulation method, J. Membrane Sci., 70 (1992) 17-30.

6 H.E.A. Brüschke, Mehrschichtige Membran und ihre Verwendung zur Trennung von Flüssigkeitsgemischen nach dem Pervaporationsverfahren, German Patent DE 3220570 A1, 1983.

7 J.M.S. Henis and M.K. Tripodi, Composite hollow fiber membranes for gas separation: the resistance model approach, J. Membrane Sci., 8 (1981) 233.

8 M.H.V. Mulder, F. Kruitz and C.A. Smolders, Separation of isomeric xylenes by pervaporation through cellulose ester membranes, J. Membrane Sci., 11 (1982) 349.

9 G.H. Koops, J.A.M. Nolten, M.H.V. Mulder and C.A. Smolders, Selectivity as a function of membrane thickness: gas separation and pervaporation, J. Appl. Polym. Sci., submitted.

10 J.-P. Brun, C. Larchet, R. Melet and G. Bulvestre, Modelling of the pervaporation of binary mixtures through moderately swelling, non-reactive membranes, J. Membrane Sci., 23 (1985) 257-283.

11 G.H. Koops, Dehydration of acetic acid by pervaporation: material science aspects, Ph.D. Thesis, University of Twente, Enschede, The Netherlands, 1992, Chap. 2. 


\section{Appendix}

The "exponential 6-parameter model" of Brun et al. [10] applied to the separation of acetic acid/water mixtures using dense PVC and dense PAN membranes

According to Fick the component fluxes for a binary mixture through a membrane can be described by the following relation

$J_{i}=-D(c)_{i} \frac{\mathrm{d}\left(C_{i}\right)}{\mathrm{d} z}$

where $D_{i}$ is a function of the component concentration. For both components $i$ and $j$ the diffusion coefficient can be expressed by

$D_{i}=D_{i, 0} \exp \left(A_{i i} C_{i}+A_{i j} C_{j}\right)$

$D_{j}=D_{j, 0} \exp \left(A_{j i} C_{i}+A_{j j} C_{j}\right)$

The molar flux ratio $J_{i} / J_{j}$ is constant across the whole membrane and can now be expressed by

$\frac{J_{i}}{J_{j}}=\frac{D_{i, 0} \exp \left(K_{i} C_{i}\right) \mathrm{d} C_{i}}{D_{j, 0} \exp \left(K_{j} C_{j}\right) \mathrm{d} C_{j}}$

with:

$K_{i}=A_{i i}-A_{j i}$

$K_{j}=A_{j j}-A_{i j}$

Integrating across the membrane results in the following expression for the component flux ratio

$\frac{J_{i}}{J_{j}}=\frac{D_{i, 0} K_{j}}{D_{j, 0} K_{i}}\left[\frac{\exp \left(K_{i} \overline{C_{i}^{\mathrm{p}}}\right)-\exp \left(K_{i} \overline{C_{i}^{\mathrm{f}}}\right)}{\exp \left(K_{j} \overline{C_{j}^{\mathrm{p}}}\right)-\exp \left(K_{j} \overline{C_{j}^{\mathrm{f}}}\right)}\right]$

The concentration can be written in terms of activity using the following relation

$C=S a$

relation (A5) then becomes

$$
\frac{J_{i}}{J_{j}}=\frac{D_{i, 0} K_{j}}{D_{j, 0} K_{i}}\left[\frac{\exp \left(K_{i} S_{i} a_{i}^{\mathrm{p}}\right)-\exp \left(K_{i} S_{i} a_{i}^{\mathrm{f}}\right)}{\exp \left(K_{j} S_{j} a_{j}^{\mathrm{p}}\right)-\exp \left(K_{j} S_{j} a_{j}^{\mathrm{f}}\right)}\right]
$$

By the following substitutions

$$
\begin{aligned}
& m_{1}=\frac{D_{i, 0} K_{j}}{D_{j, 0} K_{i}} \\
& m_{2}=K_{i} S_{i} \\
& m_{3}=K_{j} S_{j}
\end{aligned}
$$

relation (A7) is simplified and becomes now

$\frac{J_{i}}{J_{j}}=m_{1}\left[\frac{\exp \left(m_{2} a_{i}^{\mathrm{p}}\right)-\exp \left(m_{2} a_{i}^{\mathrm{f}}\right)}{\exp \left(m_{3} a_{i}^{\mathrm{p}}\right)-\exp \left(m_{3} a_{i}^{\mathrm{f}}\right)}\right]$

If the activities at the permeate side are considered as being equal to zero the constants $m_{1}$, $m_{2}$ and $m_{3}$ can be determined by fitting relation (A11) to the experimentally determined component flux ratios as a function of $a_{i}^{f}$. Therefore, $a_{j}^{\mathrm{f}}$ has to be expressed as a function of $a_{i}^{\mathrm{f}}$. This relation can be found from equilibrium sorption experiments in liquid mixtures at different activities.

This has been done for acetic acid/water mixtures using PVC and PAN as membrane

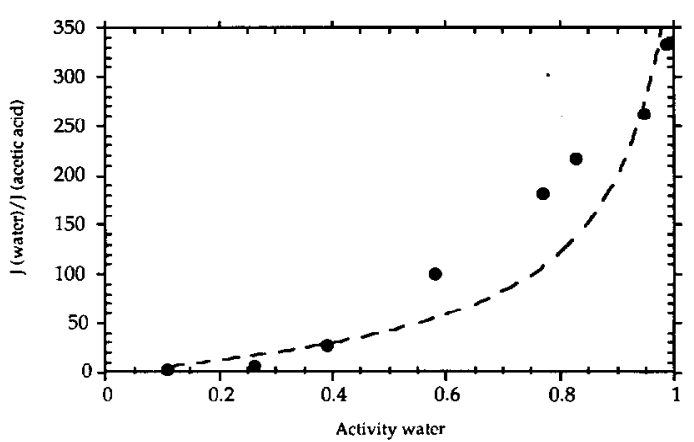

Fig. A1. The water and acetic acid flux ratio as a function of the water activity in the feed mixture for water/acetic acid separation by pervaporation at $80^{\circ} \mathrm{C}$ using a PVC membrane; dots (experimental values), line (fitted relation ). $m_{1}=21.4100, m_{2}=0.04045, m_{3}=0.01517$. 


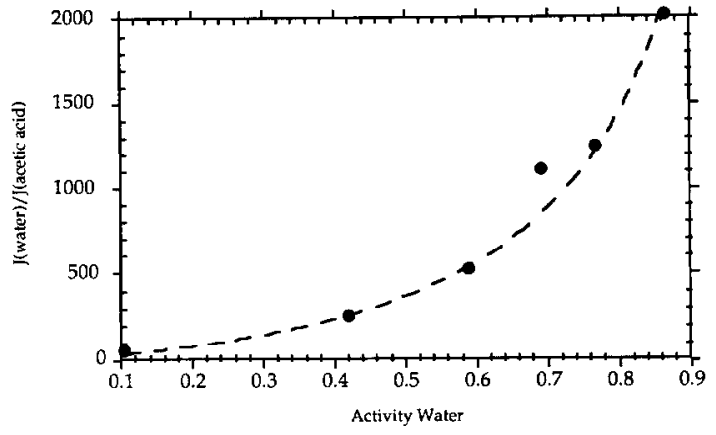

Fig. A2. The water and acetic acid flux ratio as a function of the water activity in the feed mixture for water/acetic acid separation by pervaporation at $80^{\circ} \mathrm{C}$ using a PAN membrane; dots (experimental values), line (fitted relation). $m_{1}=1.67486, m_{2}=1.75428, m_{3}=0.00931$.

materials [11]. For the water activity range of 0.1 to 1 the following relations for $a_{\mathrm{a}}^{\mathrm{f}}$ as a function of $\boldsymbol{a}_{\mathrm{w}}^{\mathrm{f}}$ can be obtained
PVC: $a_{\mathrm{a}}^{\mathrm{f}}=1.8880 \mathrm{e}^{-3}+7.9140 \mathrm{e}^{-3} a_{\mathrm{w}}^{\mathrm{f}}$

$$
-1.9023 \mathrm{e}^{-3}\left(a_{\mathrm{w}}^{\mathrm{f}}\right)^{2} \quad(R=0.998)
$$

PAN: $a_{\mathrm{a}}^{\mathrm{f}}=5.3615^{-3}-3.0145 \mathrm{e}^{-2} a_{\mathrm{w}}^{\mathrm{f}}$

$$
+0.15904\left(a_{\mathrm{w}}^{\mathrm{f}}\right)^{2} \quad(R=0.998)
$$

where $R$ represents the correlation coefficient. Fitting relation (A11) using relations (A12) and (A13) results in the curves given in Fig. A1 (PVC) and Fig. A2 (PAN), respectively, together with the values for the constants $m_{1}, m_{2}$ and $m_{3}$.

From the curves fitted to the experimentally determined values it can be concluded that the water flux/acetic acid flux ratio through PVC and PAN membranes as a function of the water activity in the feed can be well described by the "exponential 6-parameter model" of Brun et al. [10]. 